\title{
What would happen to the trees and lianas if apes disappeared?
}

\author{
DAVID BEAUNE
}

\begin{abstract}
Apes, like many frugivorous animals, are crucial allies for the reproduction of several fruiting tree species. Almost all apes, however, including bonobos Pan paniscus, are threatened with extinction. How will this affect tree conservation? How can plants that are adapted to seed dispersal by apes reproduce without their dispersal vectors? At LuiKotale, in an evergreen tropical forest of the Democratic Republic of Congo, the recruitment of 22 plant species in the absence of seed dispersal was investigated under the parental canopy, where a proportion of seeds fall without horizontal dissemination. Most bonobo-dispersed plant species ( $95 \%$ of 19 species) were unable to self-recruit under the canopy. As $40 \%$ of the tree species ( $65 \%$ of trees) at LuiKotale are dispersed by bonobos there is a risk of ecosystem decay and simplification (reduced biodiversity) if Pan paniscus disappears from its natural range. The extinction of other apes from their forests could have similar consequences. The conservation of tree species, therefore, must encompass conservation of pollinators, seed dispersal vectors and other species that provide ecological services to the trees and other fruiting plants.
\end{abstract}

Keywords Africa, bonobo, Congo basin, ecosystem decay, forest ecology, Pan paniscus, seed dispersal, zoochory

\section{Introduction}

The conservation of a species is dependent upon the conservation of those species that provide it with ecological services. The question of how the extinction of one species could affect others is particularly pertinent in the case of the great apes (Hominidae: chimpanzee Pan troglodytes, bonobo Pan paniscus, gorilla Gorilla gorilla and orang-utan Pongo pygmaeus) because they play an important role as key dispersers of woody species (Wrangham et al., 1994; Voysey et al., 1999; Gross-Camp \& Kaplin, 2011; Beaune et al., 2013a,b,c; Effiom et al., 2013). This can also be

David Beaune Department of Primatology, Max Planck Institute for Evolutionary Anthropology, Leipzig, Germany, and Laboratoire Biogéosciences, UMR CNRS 6282, Université de Bourgogne, Dijon, France E-mail david.beaune@gmail.com

Received 11 May 2014. Revision requested 18 July 2014.

Accepted 6 October 2014. First published online 27 February 2015 extended to the lesser apes, the gibbons (Hylobatidae; McConkey \& Chivers, 2007). The bonobo was the last of the three African great ape species to be discovered. It is endemic to the Democratic Republic of Congo, south of the Congo River, and its habitat does not overlap with that of either chimpanzees or gorillas. Bonobos are mainly frugivorous (66\% of feeding sessions), spending c. 3.5 hours per day swallowing seeds (Plate 1), which they transport over a relatively long distance $(93 \%>100 \mathrm{~m}$; mean 1.2 $\mathrm{km}$ ). An individual will disperse $9.1 \mathrm{t}$ of seeds (11.6 million seeds $>2 \mathrm{~mm}$ in length, excluding those such as Ficus spp. and Musanga cecropioides) in its lifetime (Beaune et al., 2013b). More than 91 plant species are dispersed by bonobos through endozoochory (Beaune et al., 2013b). Passed seeds germinate more rapidly, more successfully and with greater post-dispersal survival than unpassed seeds (seeds embedded in faeces are involved in diplochory with dung beetles; Beaune et al., 2012a). In the forest of LuiKotale $40 \%$ of tree species and $65 \%$ of individual trees rely on bonobos for seed dispersal, and functional overlap between the bonobo and other frugivorous animals appears to be low (Beaune et al., 2013b,c).

The seed dispersal service provided by bonobos is of particular interest as the species is categorized as Endangered on the IUCN Red List (Fruth et al., 2008), listed on CITES Appendix I (CITES, 2014) and under Class A in the African Convention on the Conservation of Nature and Natural Resources (OAU, 2010). The population is estimated to number $29,500-50,000$ (Fruth et al., 2008). The greatest threat to the bonobo is poaching for the commercial bushmeat trade but the species' survival is also threatened by forest fragmentation and degradation. Despite international protection and local taboos bonobos are still killed in their natural habitats, including in protected areas such as Salonga National Park (Hart et al., 2008).

I assessed the ecological importance of bonobos for fruiting plants by investigating the ability of the plant community to recruit without horizontal seed dispersal (i.e. without bonobos and other seed dispersal vectors). The hypothesis is that without seed dispersal several plant species for which apes are obligate seed dispersers would not recruit under the parental tree because of density-dependent effects on the survival of seeds and seedlings. I also discuss how bonobos depend on trees in this plant-animal mutualism. 


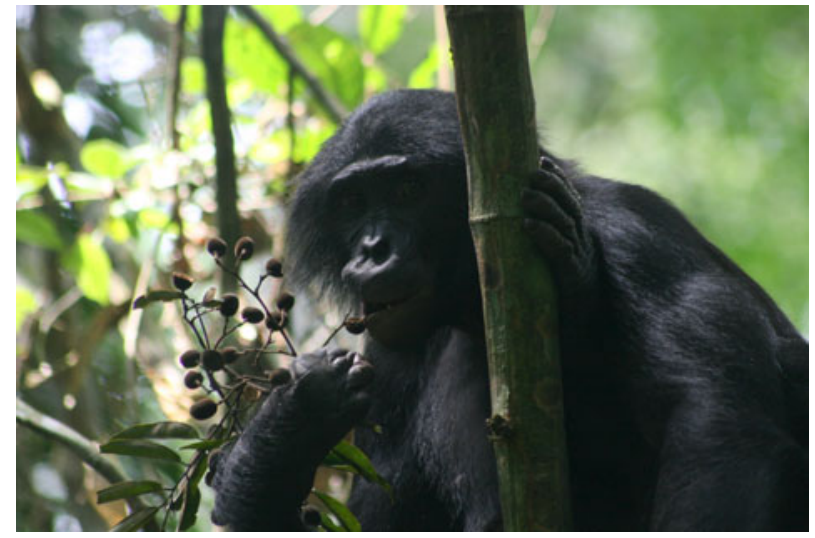

Plate 1 Bonobo Pan paniscus eating velvet tamarind fruits (Dialium sp.) and swallowing seeds at LuiKotale, Democratic Republic of Congo. Photograph: David Beaune/LKBP.

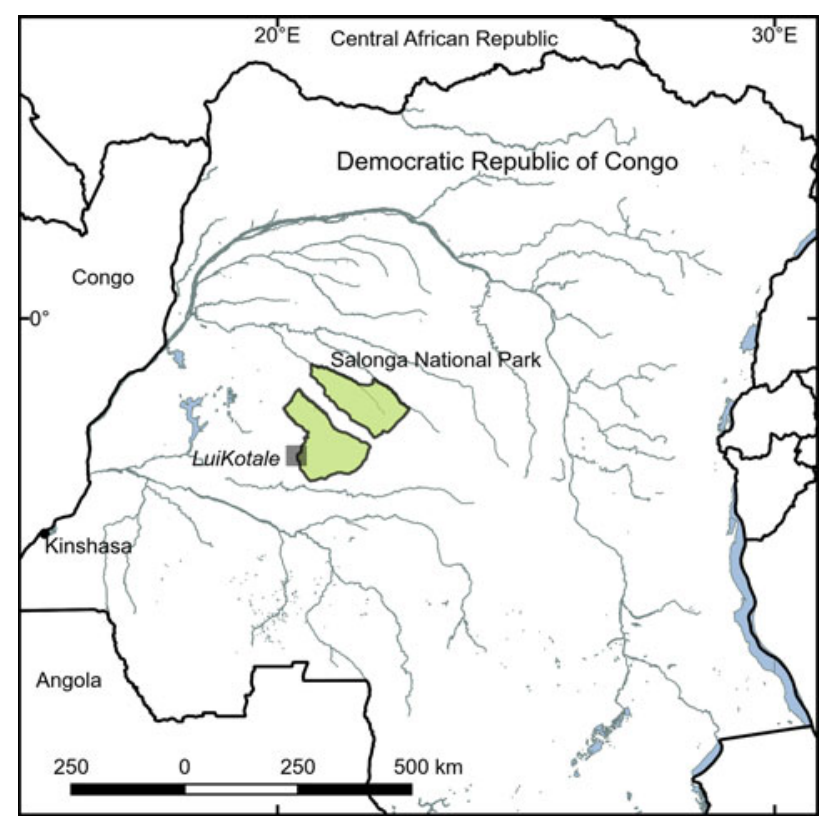

FIG. 1 Location of the study site at LuiKotale, in Salonga National Park, Democratic Republic of Congo.

\section{Study site}

Fieldwork took place at LuiKotale, at the south-western fringe of Salonga National Park, Democratic Republic of Congo (Fig. 1). The study site comprised $>100 \mathrm{~km}^{2}$ of primary evergreen lowland tropical rain forest (for more information about the study site and previous research conducted there see Beaune et al., 2012a,b,c, 2013a,b,c,d,e).

\section{Methods}

To assess seedling recruitment under the parent crown, mature trees of 22 species previously observed to fruit (thus excluding males of dioecious species) and efficiently dispersed by bonobos (Beaune et al., 2013b) were investigated during May 2010-June 2011, following the methodology of Chapman \& Chapman (1995). All seedlings $(<50 \mathrm{~cm}$ high), saplings $(50-200 \mathrm{~cm}$ high $)$ and poles $(>200 \mathrm{~cm}$ high, $<10 \mathrm{~cm}$ diameter at breast height, DBH) were censused in the parental crown area (i.e. the fruit-fall zone) of adult trees $>10 \mathrm{~cm} \mathrm{DBH}$, with no conspecifics within $10 \mathrm{~m}$ of the fruit-fall zone. The presence of seeds under the parental crown was confirmed by observation of falling seeds during animal feeding sessions and/or visual assessment of seeds present (fragments and fresh seeds). Mean numbers of seedlings, saplings and poles were calculated from a minimum of five adult plants per species. We considered an adult plant to be able to self-replace when the mean pole production per plant was $\geq 1$. To confirm that a species was able to recruit outside its fruit-fall zone, density of recruits was estimated across the total census area.

\section{Results}

Nineteen plant species (three liana and 16 tree species) were dispersed efficiently by bonobo (Table 1). Three species considered to be autochorous (i.e. dispersed by a plant's own means) were included in the assessment for comparison (see Beaune et al., 2013b,c for characterization of seed dispersal). For each plant species some seeds were not dispersed horizontally and were found under the parental crown. During bonobo and monkey (Cercopithecus cephus ascanius, Cercopithecus mona wolfi, Lophocebus aterrimus) feeding sessions broken branches and fruits with seeds (dropped or spat) from the 19 fruiting plants were observed on the ground. The autochorous species recruited, on average, more than one pole under the parents, thus fulfilling the criterion for selfreplacement. In contrast, the fleshy-fruited species dispersed by bonobos did not recruit enough poles under parent plants for self-replacement, except for Drypetes sp. (Table 1, Fig. 2). Although seedlings, saplings and poles were found under other tree species (in a total of 5.13 ha censused), most adults of zoochorous (i.e. dispersed by animals) species were not able to self-replace without seed dispersal beyond the fruit-fall zone, despite the presence of a seed bank.

\section{Discussion}

The frugivorous bonobo relies on the fruits of 107 plant species, which account for $>55 \%$ of their diet (Beaune et al., 2013b). During certain months trees such as Dialium spp. can account for $>82 \%$ of the bonobo's diet (Beaune et al., 2013d). How tree populations depend on the ecological services provided by bonobos is more difficult to assess.

However, without seed dispersal, zoochoric plant species normally dispersed by bonobo recruit insufficient young under the fruit-fall zone for self-replacement, despite 
TABLE 1 Mean number of seedlings, saplings and poles found under the canopy of adult individuals of 22 tree and liana species in LuiKotale, Democratic Republic of Congo (Fig. 1).

\begin{tabular}{|c|c|c|c|c|c|}
\hline \multirow[b]{2}{*}{ Tree species $^{1}$ (Family), limiting seed size ${ }^{2}(\mathrm{~cm})$} & \multirow[b]{2}{*}{ No. of individuals } & \multirow[b]{2}{*}{ Mean DBH $(\mathrm{cm})$} & \multicolumn{3}{|c|}{ Mean recruitment } \\
\hline & & & Seedling & Sapling & Pole \\
\hline \multicolumn{6}{|l|}{ Autochory } \\
\hline Hymenostegia mundungu (Caesalpiniaceae) & 10 & 73.7 & 4.4 & 4.1 & 2.5 \\
\hline Scorodophloeus zenkeri (Caesalpiniaceae) & 10 & 48.4 & 16.3 & 2 & 3.4 \\
\hline Strombosiopsis zenkeri (Olacaceae) & 11 & 35.6 & 2 & 2.1 & 1.2 \\
\hline \multicolumn{6}{|l|}{ Zoochory with bonobo Pan paniscus } \\
\hline Anonidium mannii (Annonaceae) $\leftrightarrow 4$ & 10 & 46.7 & 0.5 & 0.6 & 0.4 \\
\hline Blighia welwitschii (Sapindaceae) $\leftrightarrow 2$ & 5 & 62.8 & 0 & 0.2 & 0.4 \\
\hline Canarium schweinfurthii (Burseraceae) $\leftrightarrow 1.2$ & 5 & 109.4 & 0 & 0 & 0 \\
\hline Cissus dinklagei (Vitaceae) $\leftrightarrow 1$ & 5 & & 0.8 & 0 & 0 \\
\hline Drypetes sp. (Euphorbiaceae) $\leftrightarrow 1$ & 10 & 30.9 & 0.7 & 1.9 & 2.6 \\
\hline Enantia olivacea (Annonaceae) $\leftrightarrow 1$ & 6 & 15.4 & 0 & 1.8 & 0.8 \\
\hline Ficus sp. (Moraceae) ø 0.1 & 7 & & 0 & 0 & 0 \\
\hline Gambeya lacourtiana (Sapotaceae) $\leftrightarrow 1.9$ & 10 & 92.2 & 1 & 0 & 0 \\
\hline Grewia oligoneura (Malvaceae) $\leftrightarrow 2$ & 6 & 38.4 & 0.2 & 0.3 & 0.3 \\
\hline Irvingia gabonensis (Irvingiaceae) $\leftrightarrow 5$ & 54 & 83.1 & 1.7 & 0.0 & 0 \\
\hline Irvingia grandifolia (Irvingiaceae) $\leftrightarrow 5$ & 10 & 110 & 0 & 0 & 0 \\
\hline Klainedoxa gabonensis (Irvingiaceae) $\leftrightarrow 4$ & 10 & 124.5 & 0 & 0 & 0 \\
\hline Landolphia forestiana (Apocynaceae) $\leftrightarrow 1.2$ & 5 & & 0 & 0.2 & 0 \\
\hline Landolphia sp. (Apocynaceae) $\leftrightarrow 1.2$ & 5 & & 0 & 5.6 & 0.4 \\
\hline Mammea africana (Guttiferae) $\leftrightarrow 6$ & 10 & 117.6 & 0.1 & 0.9 & 0 \\
\hline Manilkara yangambiensis (Sapotaceae) $\leftrightarrow 0.9$ & 10 & 40.4 & 0.6 & 0.2 & 0.1 \\
\hline Pancovia laurentii (Sapindaceae) $\leftrightarrow 0.8$ & 10 & 27 & 0.1 & 1 & 0.5 \\
\hline Parinari excelsa (Chrysobalanaceae) $\leftrightarrow 2.3$ & 10 & 113.1 & 19.8 & 0.1 & 0.1 \\
\hline Greenwayodendron suaveolens (Annonaceae) ø1 & 10 & 29 & 0.1 & 1.6 & 0.5 \\
\hline
\end{tabular}

${ }^{1}$ Botanical nomenclature follows the African Plants Database v. 3.4.o (2014)

${ }^{2}$ The limiting greatest seed width or digestive tract passage size, indicated as diameter $(\emptyset)$ or length $(\leftrightarrow)$

regular seed restocking by gravity (barochory without zoochory/anemochory). This may be attributable to the incapacity of seeds to germinate without handling and/or to higher mortality under the parental crown as a result of density-dependent effects (Janzen, 1970; Connell, 1971; Schupp, 1992; Beaune et al., 2012c, 2013a). Bush pigs Potamochoerus porcus, giant pouched rats Cricetomys emini and 17 other seed predators at LuiKotale were observed foraging seeds under parent plants, and reduced seed survival under the parental canopy (Beaune et al., 2012a,b, 2013c). Herbivorous animals also reduced the survival of seedlings, saplings and poles, in a density-dependent effect occurring under the parent plant, where a higher density of seeds attracts more predators. An alternative way of examining this would be to compare two botanical plots from the same forest block, with and without bonobo populations, or the same plot with a before and after control impact assessment after bonobo extinction. However, this would pose ethical and logistical problems. Despite its limitations the assessment presented here gives an indication of the seed and recruitment mortality under the parental crown of species adapted to zoochory. Other, smaller seed dispersal vectors, such as monkeys, bats and birds, could fulfil the seed dispersal role of the apes for certain fruiting plants, but less effectively because the seed handling process, the dispersal distance, the number of seeds disseminated, and the secondary dispersal by dung beetles would not be equivalent. Without the bonobo more seeds would fall in the fruit-fall zone, increasing the seed bank and consequently seed mortality as a result of increased predation. A similar survey for elephant-dispersed plant species in the absence of elephants yielded the same result: the trees did not recruit sufficiently for self-replacement, and seed predation was not saturated (Beaune et al., 2013e). Fruiting plants, especially species with small seeds and several dispersal vectors, could potentially survive an extinction of the bonobo, but this needs to be investigated further. The seed dispersal service provided by bonobos could be provided by other, smaller animals but without the same dispersal effectiveness (and with potential population genetics effects on the plants). Unlike the bonobodispersed species, autochoric trees such as Hymenostegia mundungu, Scorodophloeus zenkeri and Strombosiopsis zenkeri are adapted to short dispersal distance and their seeds probably contain antifeedant and other toxic compounds. 


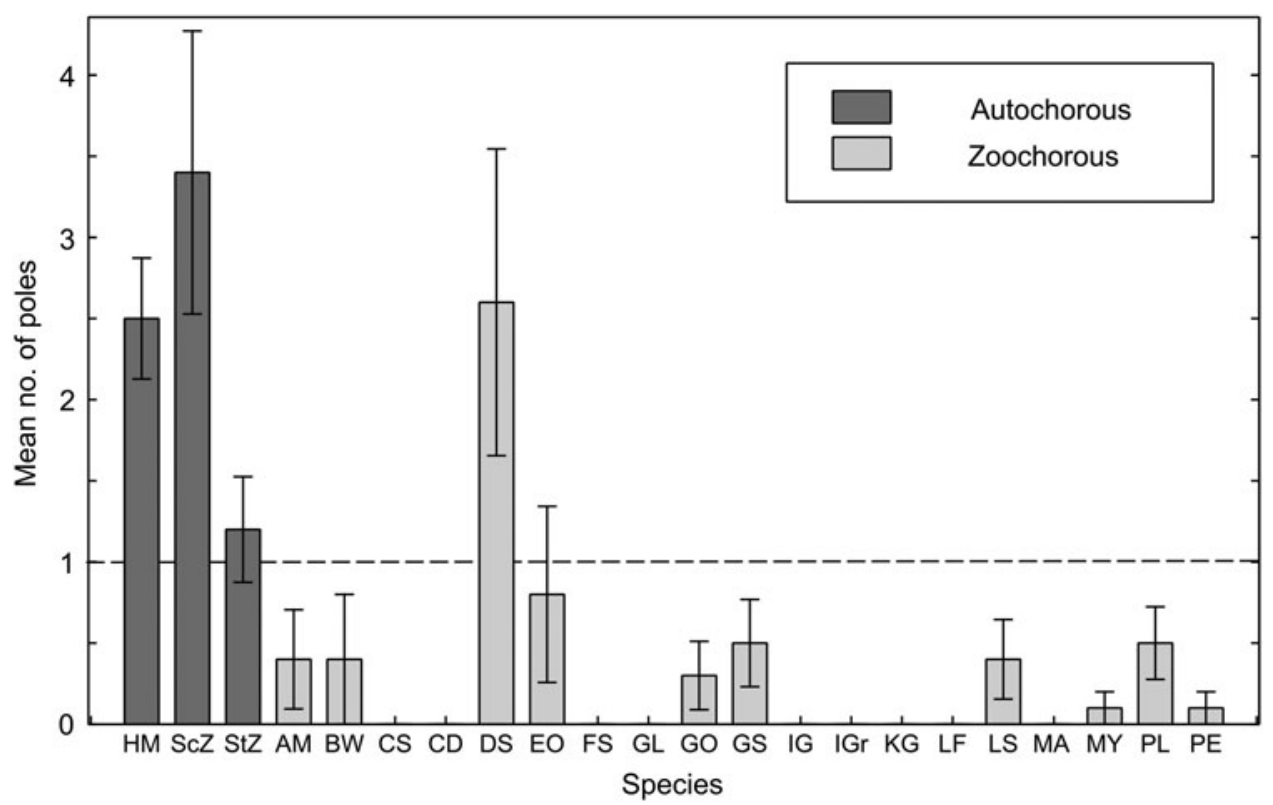

Fig. 2 Mean $( \pm \mathrm{SE})$ recruitment of poles $(<10 \mathrm{~cm} \mathrm{DBH})$ under the parent crown for three autochorous species (HM, Hymenostegia mundungu; ScZ, Scorodophloeus zenkeri; StZ, Strombosiopsis zenkeri) and 19 species dispersed by bonobos Pan paniscus (AM, Anonidium mannii; BW, Blighia welwitschii; CS, Canarium schweinfurthii; CD, Cissus dinklagei; DS, Drypetes sp.; EO, Enantia olivacea; FS, Ficus sp.; GL, Gambeya lacourtiana; GO, Grewia oligoneura; GS, Greenwayodendron suaveolens; IG, Irvingia gabonensis; IGr, Irvingia grandifolia; KG, Klainedoxa gabonensis; LF, Landolphia forestiana; LS, Landolphia sp.; MA, Mammea africana; MY, Manilkara yangambiensis; PL, Pancovia laurentii; PE, Parinari excelsa) at LuiKotale (Fig. 1). The dotted line is the threshold for self-replacement of the parent.

Preserving protected areas from deforestation but not from poaching can lead to the so-called empty forest syndrome (Redford, 1992). With bushmeat trafficking affecting apes and other dispersal vectors in many forests (Bowen-Jones \& Pendry, 1999; Fa et al., 2005; Nuñez-Iturri \& Howe, 2007; Wright et al., 2007; Brodie et al., 2009; Vanthomme et al., 2010; Effiom et al., 2013), apparently healthy adult tree populations may be threatened with extinction. Is the future of the tropical forest one of ecosystem simplification favouring autochoric and anemochoric species? Conservation strategies for apes need to include tree conservation, just as conservation of trees and other fruiting plants must include conservation of apes and other seed-dispersal vectors.

\section{Acknowledgements}

I thank the Institut Congolais pour la Conservation de la Nature for granting permission to conduct research at Salonga National Park, and the people of Lompole for granting permission to access the forest of their ancestors. Research at LuiKotale was conducted under the auspices and with the financial support of the Max Planck Society, the German Ministry of Education and Research, le conseil régional de Bourgogne, and the SFE and SFDP (France). I thank the international and local staff of LuiKotale, Gottfried Hohmann, Barbara Fruth, Loïc Bollache and François Bretagnolle for their support.

\section{References}

African Plants Database (2014) African Plants Database v. 3.4.o. Conservatoire et Jardin botaniques de la Ville de Genève and South African National Biodiversity Institute, Pretoria. Http://www. ville-ge.ch/musinfo/bd/cjb/africa/ [accessed 25 November 2014].

Beaune, D., Bollache, L., Bretagnolle, F. \& Fruth, B. (2012a) Dung beetles are critical in preventing post-dispersal seed removal by rodents in Congo rain forest. Journal of Tropical Ecology, 28, 507510 .

Beaune, D., Bollache, L., Fruth, B. \& Bretagnolle, F. (2012b) Bush pig (Potamochoerus porcus) seed predation of bush mango (Irvingia gabonensis) and other plant species in Democratic Republic of Congo. African Journal of Ecology, 50, 509-512.

Beaune, D., Bollache, L., Fruth, B., Hohmann, G. \& Bretagnolle, F. (2012c) Density-dependent effect affecting elephant seed-dispersed tree recruitment (Irvingia gabonensis) in Congo forest. Pachyderm, 52, 97-100.

Beaune, D., Bollache, L., Muganza, M.D., Bretagnolle, F., Hohmann, G. \& Fruth, B. (2013a) Artificial germination activation of Dialium corbisieri by imitation of ecological process. Journal of Sustainable Forestry, 32, 565-575.

Beaune, D., Bretagnolle, F., Bollache, L., Bourson, C., Hohmann, G. \& Fruth, B. (2013b) Ecological services performed by the bonobo (Pan paniscus): seed dispersal effectiveness in tropical forest. Journal of Tropical Ecology, 29, 367-380.

Beaune, D., Bretagnolle, F., Bollache, L., Hohmann, G., Surbeck, M. \& Fruth, B. (2013c) Seed dispersal strategies and the threat of defaunation in a Congo forest. Biodiversity and Conservation, 22, 225-238.

Beaune, D., Bretagnolle, F., Bollache, L., Hohmann, G., Surbeck, M., Bourson, C. \& Fruth, B. (2013d) The bonobo- 
dialium positive interactions: seed dispersal mutualism. American Journal of Primatology, 75, 394-403.

Beaune, D., Fruth, B., Bollache, L., Hohmann, G. \& Bretagnolle, F. (2013e) Doom of the elephant-dependent trees in a Congo tropical forest. Forest Ecology and Management, 295, 109-117.

Bowen-Jones, E. \& Pendry, S. (1999) The threat to primates and other mammals from the bushmeat trade in Africa, and how this threat could be diminished. Oryx, 33, 233-246.

Brodie, J.F., Helmy, O.E., Brockelman, W.Y. \& Maron, J.L. (2009) Bushmeat poaching reduces the seed dispersal and population growth rate of a mammal-dispersed tree. Ecological Applications, 19, $854-863$

Chapman, C.A. \& Chapman, L.J. (1995) Survival without dispersers: seedling recruitment under parents. Conservation Biology, 9, 675678.

CITES (2014) Convention on International Trade in Endangered Species of Wild Fauna and Flora. Appendices I, II and III. Http:// cites.org/eng/app/appendices.php [accessed 24 November 2014].

Connell, J.H. (1971) On the role of natural enemies in preventing competitive exclusion in some marine mammals and in rain forest trees. In Dynamics of Populations (eds P.J. Boer \& G. Gradwell), pp. 298-310. PUDOC, Wageningen, Netherlands.

Effiom, E.O., Nuñez-Iturri, G., Smith, H.G., Ottosson, U. \& Olsson, O. (2013) Bushmeat hunting changes regeneration of African rainforests. Proceedings of the Royal Society B, 280, 20130246.

FA, J.E., Ryan, S.F. \& BeLL, D.J. (2005) Hunting vulnerability, ecological characteristics and harvest rates of bushmeat species in afrotropical forests. Biological Conservation, 121, 167-176.

Fruth, B., Benishay, J.M., Bila-Isia, I., Coxe, S., Dupain, J., Furuichi, T. et al. (2008) Pan paniscus. IUCN Red List of Threatened Species v. 2014.3. Http://www.iucnredlist.org [accessed 24 November 2014].

Gross-Camp, N.D. \& Kaplin, B.A. (2011) Differential seed handling by two African primates affects seed fate and establishment of large-seeded trees. Acta Oecologica, 37, 578-586.

Hart, J.A., Grossmann, F., Vosper, A. \& Ilanga, J. (2008) Human hunting and its impact on bonobos in the Salonga National Park, Democratic Republic of Congo. In The Bonobos: Behavior, Ecology, and Conservation (eds T. Furuichi \& J. Thompson), pp. 245-272. Springer, New York, USA.

JAnZEN, D.H. (1970) Herbivores and the number of tree species in tropical forests. The American Naturalist, 104, 501-528.

McConkey, K.R. \& Chivers, D.J. (2007) Influence of gibbon ranging patterns on seed dispersal distance and deposition site in a Bornean forest. Journal of Tropical Ecology, 23, 269-275.

Nuñez-Iturri, G. \& Howe, H.F. (2007) Bushmeat and the fate of trees with seeds dispersed by large primates in a lowland rain forest in western Amazonia. Biotropica, 39, 348-354.

OAU (Organisation of African Unity) (2010) African Convention on the Conservation of Nature and Natural Resources. Http://www.african-court.org/pt/images/documents/Sources\%20of \%2oLaw/Conservation\%20of\%20Nature/nature\%2oeng.pdf [accessed 24 November 2014].

Redford, K.H. (1992) The empty forest. BioScience, 42, 412-422. Schupp, E.W. (1992) The Janzen-Connell model for tropical tree diversity: population implications and the importance of spatial scale. The American Naturalist, 140, 526-530.

Vanthomme, H., Bellé, B. \& Forget, P.-M. (2010) Bushmeat hunting alters recruitment of large-seeded plant species in Central Africa. Biotropica, 42, 672-679.

Voysey, B.C., McDonald, K.E., Rogers, M.E., Tutin, C.E.G. \& PARnELl, R.J. (1999) Gorillas and seed dispersal in the Lopé Reserve, Gabon. I: gorilla acquisition by trees. Journal of Tropical Ecology, 15, 23-38.

Wrangham, R.W., Chapman, C.A. \& Chapman, L.J. (1994) Seed dispersal by forest chimpanzees in Uganda. Journal of Tropical Ecology, 10, 355-368.

Wright, S.J., Hernandéz, A. \& Condit, R. (2007) The bushmeat harvest alters seedling banks by favoring lianas, large seeds, and seeds dispersed by bats, birds, and wind. Biotropica, 39, 363-371.

\section{Biographical sketch}

DAVID BEAUNE specializes in conservation and ecological services. His interests cover various ecosystems and species, from the poles to the equator. He is working to establish a scientific organization to facilitate a positive anthropogenic effect on the environment. 